\title{
Budget Management of Chinese Institutions
}

\author{
Wei Mu \\ Nanjing University of Science and Technology \\ Nanjing, China
}

\begin{abstract}
In China, institution is an important carrier for providing public services. With the development of economy and the increasing demand for public services, Chinese institutions have been developing rapidly. However, the level of financial management of institutions is not compatible with the growth of their financial resources. With the economic activities involved in the increasingly complex internal and external relations, Chinese institutions have not only the phenomenon of waste of resources, but also the issue of corruption. Budget management is the starting point of all economic activities of institutions as well as the core part of the establishment and implementation of internal control. This paper first systematically combs the policy changes of the budget management of Chinese institutions, and then makes a deep exposition on the existing problems of Chinese institutions based on the budget management process, which are budget compilation, budget implementation and budget performance evaluation. Finally the paper puts forward the concrete measures in terms of government and corporate respectively.
\end{abstract}

Keywords - Chinese institutions; budget policy changes; budget management

\section{INTRODUCTION}

The institution budget consists of income budget and expenditure budget. Income budget includes income from financial subsidies, appropriation of funds, operating income, income from subordinate units, other income, etc.; expenditure budget includes appropriation, business expenses, operating expenses, cost, sales tax, subsidy to subordinate units, surrender of higher expenses, carry forward self-financing infrastructure, etc. To understand the budget of Chinese institutions, we should start from the process of the national budget policy reforms and analyze the requirements made by government to the budget of institutions so as to objectively reflect the feasibility of budget policies in practice and provide reasonable advice on the improvement of budget management policies.

In 2000, the departmental budget reform had an important impact on the budget of Chinese institutions. The departmental budgets have refined budgetary spending, which is divided into basic expenditure and project expenditure, changed the budget cycle, and highlighted the importance of zero-based budgeting. In 2001, the central government began to start the treasury centralized payment system reform, followed by the implementation of the government revenue and expenditure classification reform. In 2002, China joined the International Monetary Fund, in order to adapt to domestic and international environmental changes, budget disclosure system was introduced, and the allocation of "three public" funds was viewed as a breakthrough in the budget open reform. Three public funds refer to go abroad (border) funds consumed by the government staff for work, the purchase of official vehicles and operating costs, official hospitality. In 2005, the Ministry of Finance formulated "Measures for the Administration of Performance Evaluation of Budgetary Expenditure in Central Departments (for Trial Implementation)", which began the exploration of budget performance management. The new budget law implemented in 2015 has made a number of major breakthroughs. The most important point is that medium-term financial planning was proposed, which could provide the necessary support for the performance evaluation of institutions combined with their long-term goals. But how to establish a cross-annual balance mechanism is still a complicated question.

The series of reforms of Chinese budget policies have made great progress on the integrity, transparency, normality and how to strengthen the supervision of institutions. But a number of policies are still the pilot projects or under exploration. For examples, the specific operation of the zerobased budget, uniform indicators and evaluation methods of budget performance evaluation, a cross-annual balance mechanism to promote medium-term financial planning are all not clearly defined. These need both the government and institutions to improve the combination of policy construction and practical application. In order to promote the development of budget management in institutions, how to make the improvement in government and institutions respectively is the main content of this paper.

\section{THE PROBLEMS OF BUdget MANAGEMENT}

Budget management process can be simplified to the three main steps, namely budget compilation, budget implementation and budget evaluation. The improvement of the budget management of institutions needs to be analyzed separately from these three aspects.

\section{A. Problems in the Budget Compilation of Institutions}

Budget compilation is the starting point of budget management, which determines whether other links of budget management process can be implemented smoothly. The budget management mechanism, which is an important guarantee for the good functioning of all links of the budget management especially in budget compilation, generally includes decision-making bodies, management processes, personnel quality and information systems. 
As for the deficiencies of budget management mechanism, there are three aspects need to be pointed out. Firstly, at present, institutions are generally not set up budget agencies or departments. The financial sector, which is responsible for all budget activities, cannot fully understand the development strategy and business operations. What's more, the role of the finance sector in budget management is both an athlete and a referee, contrary to the principle of the separation of incompatible duties. Secondly, budget compilers do not pay much attention to cultivate themselves about knowledge of the overall business situation and long-term planning awareness. Lastly, China's institutions have been fully completed the accounting computerization, but there are still many deficiencies. For examples, there is no sharing information with the business sector, no database established as a basis for budget model building, the lack of timely dynamic comparison between budget and accounting information, the lack of complex financial analysts.

In terms of the technical method of budget compilation, the current budgeting process is still in transition from the base budget to the zero-based budget, which does not work very well. The factors are as followed. Firstly, information asymmetry between financial sector and operating department as well as the lack of effective means of verification lead to the uncertainty of the quota standard and the inaccuracy of the project budget. Secondly, institutions put more emphasis on the funds input than the effect. For the difference between the budget and the budget, they often focus on analyzing the reasons without effective solutions. Lastly, the relevant regulations of budget compilation time are not reasonable. The budget compilation is generally beginning in October of this year and needs to be reported within 1 month. In that case, the next year's work tasks are not yet fully clear, resulting that the budgeting and annual works cannot match each other.

\section{B. Problems in the Budget Implementation of Institutions}

Budget implementation is the next link after the budget compilation and approval. The Problems in the budget Implementation reflect in two aspects. On one hand, some factors involved in budget compilation and approval make budget Implementation difficult. On the other, there is no strict supervision mechanism on budget Implementation.

Due to Short budgeting time, Budget reporting tends to be relatively simple and rough. After the approval of the budget, the business department cannot implement the budget in time, because they need to demonstrate and refine again, which results in budget implementation lag and differences between budget implementation and budget compilation. Another problem is that the result of the budget approval is issued too late. Budget implementation has been conducted to the second quarter, the year of April and May, so this situation objectively caused the phenomenon of spending money quickly at the end of year.

In the process of budget implementation, the budget supervision department should supervise the whole process of the budget, on the one hand to supervise the use of budget funds and prevent budget overruns; the other hand, to regularly review the budget implementation and ensure the consistency of the budget implementation and strategy planning. However, the budget supervision on institutions is not satisfactory. In addition, complex budget approval process causes the lake of timely analysis and reasonable adjustments, when external environment and other uncertain factors appear, to ensure the expected performance and strategic objectives.

\section{Problems in the Performance Evaluation of Institutions}

With the promulgation of the new budget law in China, institutions are required to compile performance budgets for projects with large amounts. However, this provision is not implemented for a long time, so the institutions have not enough enthusiasm to explore the establishment of the performance objectives and evaluation indicators. The unity of evaluation methods and the use of evaluation results are still in the exploratory stage. Specifically, the performance evaluation is not linked to the amount of funds allocated.

The evaluation of budget performance should be divided into two parts, one is the budget performance evaluation of a single project, such as the mid-term report and the final acceptance report of a project; the other is the departmental budget performance evaluation, which aims to ensure the realization of the budget performance targets and department strategy development goals. At present, the performance evaluation for the second part has not yet been implemented.

\section{The MEAsures of Budget Management}

The essence of budget management is the pursuit of the authenticity and rationality of the budget. On the one hand, budget management requires government to give proper guidance and supervision by policy formulation and legal constraints; on the other hand it also requires institutions to hold their own correct budget ideas and effective improvement measures.

\section{A. Government Level}

- Firstly, the government should improve the budget management policies and strengthen the budget supervision. Specific budgetary policies and rigorous budget regulation are important external forces to ensure the effectiveness of budget control. Although series of reforms of Chinese budget policies have made great progress, some policies are still in the process of pilot and exploration without the specific practical steps, result in the leaders of institutions still lack budget performance awareness. Therefore, the government should specify the contents of supervision, such as the purpose of the use of funds, such as whether the special funds would be used according to the original target and whether internal control is complete. The results of the budget performance evaluation should be linked to the adjustment of the allocation coefficient. Put an end to formalism phenomenon of government regulation.

- Secondly, the government should improve the mediumterm financial planning framework, and strengthen the link between the budgeting and the development strategy. According to the relevant provisions, the medium-term financial planning requires institutions to 
compile cross-year planning, which based on the annual budget and combined with the next three years of financial and expenditure needs. The government should re-consider the rationality of the annual budget according to the medium-term financial plan, promote the annual column-based budgeting method based on the medium-term budget, refine the medium-term budget compilation, combine the annual budget target with the strategic planning, and strengthen the mid-term financial planning constraints on the annual budget.

- Thirdly, the government should strengthen the disclosure of financial information and improve the transparency of budget information. China's provincial governments publish about $1 / 3$ of the financial information, from the international point of view, the transparency at a low level. The low transparency of budget information also hinders the effective implementation of external oversight. The government should first publish institutions' budget and final account information to establish financial information publicity system and platform, and then publish the results of budget performance evaluation of institutions.

\section{B. Institutions Lever}

- Firstly, institutions should improve the budget management system and the information level of budget management. Specifically, institutions should set up a separate budget management sector or budget management committee, which parallels to the financial institution. Establish an internal oversight organization to inspect and supervise the whole process of budget. At the same time, institutions should use the information technology for data preservation, transmission and analysis to standardize budgeting and implementation process.

- Secondly, institutions should take correspondent measures of three parts of budget process. As for budget compilation, the four budgeting methods of incremental budget, zero-based budget, rolling budget and performance budget should be combined with each other to strengthen the effective convergence of longterm strategy, medium-term planning and short-term plan. As for budget Implementation, it should take into account the technological progress, project adjustment, price changes and many other uncontrollable factors, to maintain the flexibility of the budget implementation. Institutions should establish a real-time tracking and monitoring system to ensure the collection of first-hand data is true and reliable. At the same time, institutions must continue to standardize the relevant provisions to reduce the budget irregular adjustment. As for budget performance evaluation, the relevant personnel should reasonably select the budget performance evaluation index of institutions. According to the different subjects and objects of the performance evaluation of institutions, it can be divided into two parts, the project budget performance evaluation and the departmental budget performance evaluation respectively, and set the weight reasonably according to the two levels of the financial and business evaluation indexes.

- Thirdly, institutions should improve the quality of budget participants. In the interaction between the upper and lower levels, the leadership think highly of the budget management can increase budget participation of overall department staff. Both the professional abilities and ethics of budget participants can affect the authenticity of the budget, so staff quality training is significant. Institutions should create a favorable environment to promote communication between employees in various departments, to achieve mutual understanding between budget compilers and business units and to increase the accuracy of budgeting as well as the timeliness of budgetary performance feedback.

\section{CONCLUSION}

This paper systematically combs the policy changes of the budget management of Chinese institutions, and makes a deep exposition on the existing problems of Chinese institutions based on the budget management process. Through the analysis of these problems, the paper puts forward the concrete measures. There are still many gaps and ambiguities in the budget management of institutions, and there are still many debates and problems in practice, which is a very worthy area of study. This article is based on the theoretical level of analysis, and follow-up research can explore the practical application. For each part of the budget management of institutions, specific and feasible budget management operation manuals should be gradually established, and continue to improve after the trial of some institutions.

\section{REFERENCES}

[1] M Covaleski,JHE lii,J Luft,MD Shields.Budgeting Research: Three Theoretical Perspectives and Criteria for Selective Integration[J].Handbooks of Management Accounting Research, 2006, 2(1):587-624.

[2] Pounder J. S. Evaluating the relevance of quality to institutional performance assessment in higher education [J]. Evaluation, 2000, 6(01):66-78.

[3] Poister T. H., Pitts D. W., \& Edwards L. H. Strategic Management Research in the Public Sector: A Review, Synthesis, and Future Directions [J]. The American Review of Public Administration in Social Work, 2010, 40(05):522-545

[4] Douglas E. Stevens. The effects of reputation and ethics on budgetary slack [J].Journal of Management Accounting Research, 2002, (14):153171.

[5] Van der Stede W.A. The relationship between two consequences of budgetary controls:budgetary slack creation and managerial short-term orientation [J]. Accounting, Organizations and Society, 2000, (25):609622.

[6] Fisher J. G., S. A. Peffer and G. B. Sprinkle. Budget-based contracts, budget levels, and group performance [J].Journal of Management Accounting Research, 2003(15):51-74.

[7] Tapinos E., Dyson R., \& Meadows M. The impact of performance measurement in strategic planning [J]. International Journal of Productivity and Performance Management, 2005 (05/06):370-384. 